\title{
CONCOMITANT COMBINED DEGENERATIVE COMPRESSION OF THE SPINAL CORD AND CAUDA EQUINA: A REPORT ON THREE CASES
}

\author{
Atanas Davarski ${ }^{1}$, Ivo Kehayov ${ }^{1}$, Tanya Kitova ${ }^{2}$, Christo Zhelyazkov ${ }^{1}$, Borislav Kitov \\ ${ }^{1}$ Department of Neurosurgery, ${ }^{2}$ Department of Anatomy, Histology and Embryology, \\ Medical University of Plovdiv,
}

\begin{abstract}
We report on three cases with concomitant combined degenerative compression of the spinal cord and cauda equina which were diagnosed and operated in a single stage. The first case presents left-sided paramedian disc herniations at $L_{1-2}$ and $L_{4-5}$ levels, combined with concurrent degenerative spinal stenosis. The second case includes right-sided paramedian disc herniation at $\mathrm{Th}_{12}-\mathrm{L}_{1}$ level in combination with severe degenerative lumbar spinal stenosis at $\mathrm{L}_{3-4}$ level. The third case describes advanced degenerative compression at $\mathrm{Th}_{7-8}$ level with concurrent central spinal stenosis at $L_{4-5}$ level.

We have discussed the clinical presentation of concurrent combined symptomatic degenerative compression of the spinal cord and cauda equina which can deceive the physician and lead to omitted diagnosis of the thoracic compression.

In an attempt to avoid misdiagnosis of thoracic degenerative compression, it is necessary to perform thorough neurological examination of the spinal cord motor and sensory functions. In addition, further MRI examination of upper spinal segments is needed, if previous studies of the lumbar spine fail to provide reasonable explanation for the existing neurological symptoms.
\end{abstract}

Key words: thoracic spinal stenosis, lumbar spinal stenosis, myelopathy, radiculopathy

\section{INTRODUCTION}

Degenerative spinal stenosis in the lumbar region can sometimes be combined with degenerative narrowing of the spinal canal in the thoracic or thoraco-lumbar region which can result from ossification of the flavum ligament or the posterior longitudinal ligament $(1,2)$, herniated disc (3), arachnoid

Address for correspondence:

Ivo Kehayov

Medical University of Plovdiv

Department of Neurosurgery

Bul. Vasil Aprilov 15-A

Plovdiv 4002

e-mail:dr.kehayov@gmail.com

Received: May 12, 2014

Accepted: September 10, 2014 cysts (4), or spinal tumor (5-7). The term "tandem spinal stenosis" has found its place in the literature and usually refers to the concomitant combined narrowing of the spinal canal in the cervical and lumbar regions, but similar degenerative combined compressions can be observed in the thoracic, thoraco-lumbar and lumbar regions (3-9). Most of the cases with symptomatic degenerative compression in the lumbar spine are amenable to surgical decompression. Unfortunately, in some cases neurological deterioration can occur postoperatively as a consequence of misdiagnosed concurrent upper degenerative spinal cord compression (3-7).

In the present publication, we report on three cases with concomitant degenerative compression of the spinal cord and cauda equina that were diagnosed and operated in a single stage. 


\section{Case 1}

A 72-year-old female patient has been complaining of episodic low back pain irradiating to the gluteal region and the antero-lateral surface of her left lower extremity, which has recently become weak. During the last 6 months, the pain has become severe and constant. Numbness in the left leg occurred which was followed by weakness in the left foot. At last, she also experienced pain in the right leg. The neurological examination revealed demonstrative lumbar vertebral syndrome, positive straight leg raise test (Lasegue sign) and femoral nerve stretch test on the left side, hyperalgesia and hypesthesia across the left $\mathrm{L}_{2}$ and $\mathrm{S}_{1}$ dermatomes, absent left knee jerk and ankle jerk reflexes, left peroneal nerve and right tibial nerve palsies. Marked muscle hypotrophy of the left leg was also present.

The lumbo-dorsal myelography demonstrated compression of the thecal sac at $\mathrm{L}_{4-5}$ level suggesting left paramedian disc herniation in combination with concomitant spinal stenosis that causes severe compression at $\mathrm{L}_{1-2}$ level (Fig. 1).

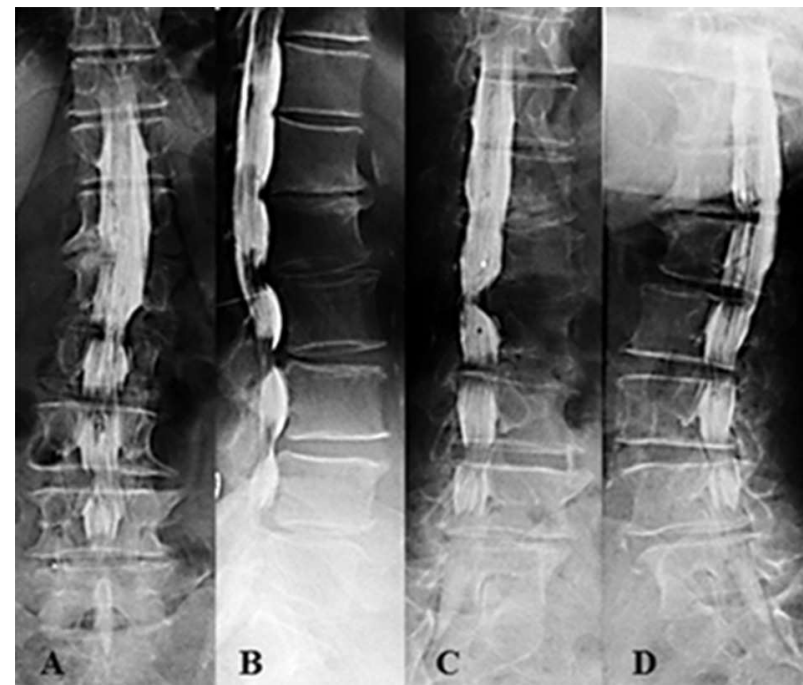

Fig. 1. Lumbo-dorsal myelography demonstrating multilevel lumbar stenosis and severe compressions of the thecal sac at L4-5 and L1-2 levels from suspected herniated discs ( $A$ - A-P projection; $B$ - Lateral projection; $C$ - Right oblique and D - Left oblique projections).

One-staged surgical decompression was performed at both levels with removal of the herniated discs. The postoperative period was uneventful. There was marked improvement of the vertebral syn- drome, the pain was significantly reduced. The peroneal and tibial palsies ameliorated.

\section{Case 2}

A 58-year-old male has been complaining of low back pain through the last year. Gradually, after trauma he started to complain of pain in the back followed by numbness and stiffness in both legs. Ten years ago, he was operated on herniated disc combined with degenerative lumbar stenosis at $\mathrm{L}_{4-5}$ level. The neurological examination revealed severe thoraco-lumbar vertebral syndrome, bilateral $\mathrm{L}_{5}$ and $\mathrm{S}_{1}$ radicular syndrome with hyperalgesia and hypesthesia, hypereflexia of the lower extremities, bilateral positive Babinski sign, conductive hypethesia distal from Th12 level, and latent inferior paraparesis (Grade D according to the Frankel Scale). The MRI of the thoraco-lumbar segment demonstrated marked degenerative lumbar spinal stenosis at L3-4 level that resulted from facet and laminar hypertrophy leading to central and foraminal stenosis in combination with spinal cord compression at $\mathrm{Th}_{12}-\mathrm{L}_{1}$ level from suspected herniated disc (Fig. 2).

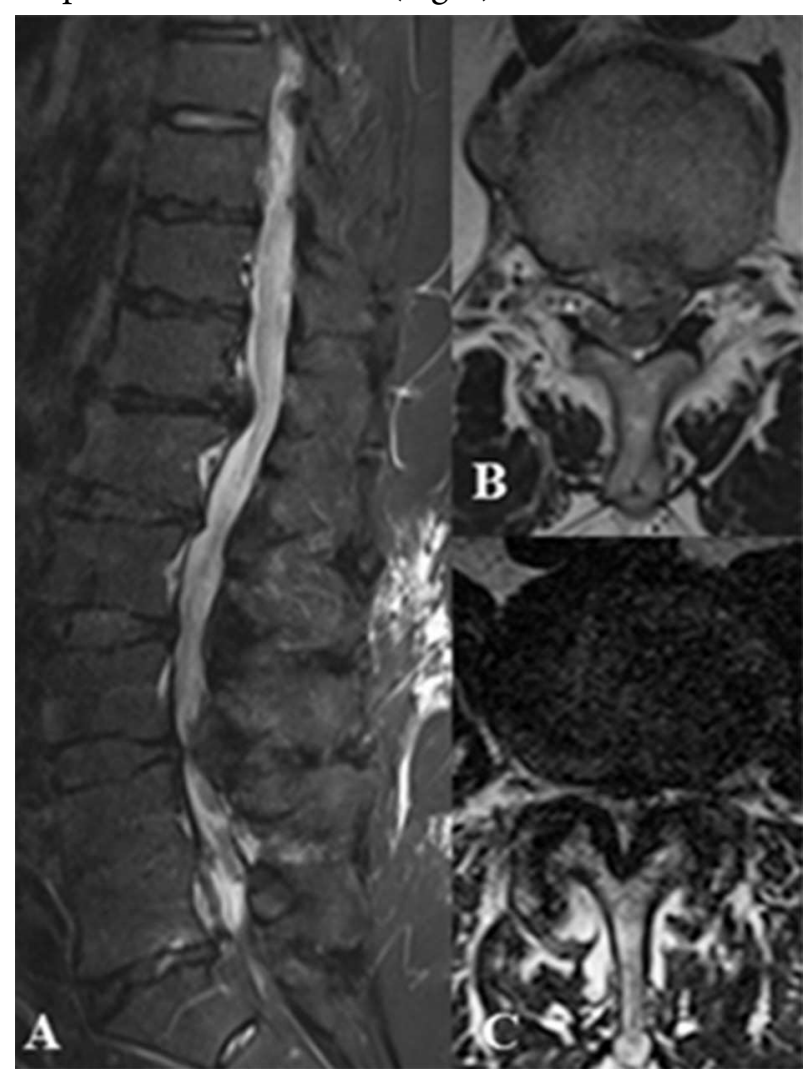

Fig. 2. MRI - A/ Sagittal view; B/ Axial view at Th12-L1 level; C/ Axial view at L3-4 level 
One-staged surgical decompression was performed at $\mathrm{L}_{3-4}$ level $\left(\mathrm{L}_{3}\right.$ laminectomy plus partial $\mathrm{L}_{4}$ laminectomy) and $\mathrm{Th}_{12}-\mathrm{L}_{1}$ level (Th12 hemilaminectomy and partial arthropediculotomy) The intraoperative finding consisted of marked degenerative lumbar spinal stenosis at $\mathrm{L}_{3-4}$ level caused by hyperthrophy of the vertebral laminae, thickening and ossification of the flavum ligament and epidural varicosis. Large right paramedian herniated disc was removed at $\mathrm{Th}_{12}-\mathrm{L}_{1}$ level.

Postoperatively, there was a substantial improvement in the pain and vertebral syndromes, reduction of the conductive hypesthesia and inferior paraparesis. There was persistent dermatomal hypesthesia along $\mathrm{L}_{5}$ and $\mathrm{S}_{1}$ dermatomes.

\section{Case 3}

A 65-year-old female patient was complaining of back and low-back pain that occasionally irradiated to the anterior and lateral surfaces of the thighs accompanied by numbness. Immediately after physical strain the day before hospital admission, she had felt acute pain in the thoraco-lumbar region accompanied by numbness, stiffness and progressive weakness of the legs which finally became fully paralyzed within hours. She was not able to voluntarily control her bladder functions. The neurological examination revealed marked thoraco-lumbar vertebral syndrome, bilateral pain and hypesthesia across the zones of $\mathrm{L}_{5}$ and $S_{1}$ dermatomes, inferior paraplegia (Grade $A$ on the Frankel Scale), conductive hypesthesia below $\mathrm{Th}_{9}$ dermatome, bilateral positive Babinski sign, retention of the urine and defecation. Computer-assisted lumbo-dorsal myelography showed marked degenerative compression at $\mathrm{Th}_{7-8}$ level and concomitant central lumbar spinal stenosis at $\mathrm{L}_{4-5}$ level with stop of the contrast agent spillage (Fig. 3 and 4).

The surgical treatment consisted of laminectomies of the $7^{\text {th }}$ and $8^{\text {th }}$ thoracic vertebra and the $4^{\text {th }}$ lumbar vertebra with left-sided arthropediculotomy at $\mathrm{Th}_{7-8}$ level. There was substantial narrowing of the spinal canal due to degeneration and hypertrophy of the vertebral laminae, facets and flavum ligament at both levels.

Postoperatively, the patient's neurological status improved to Grade $\mathrm{C}$ according to the Frankel Scale but she was unable to walk unassisted, the sensory deficit ameliorated.

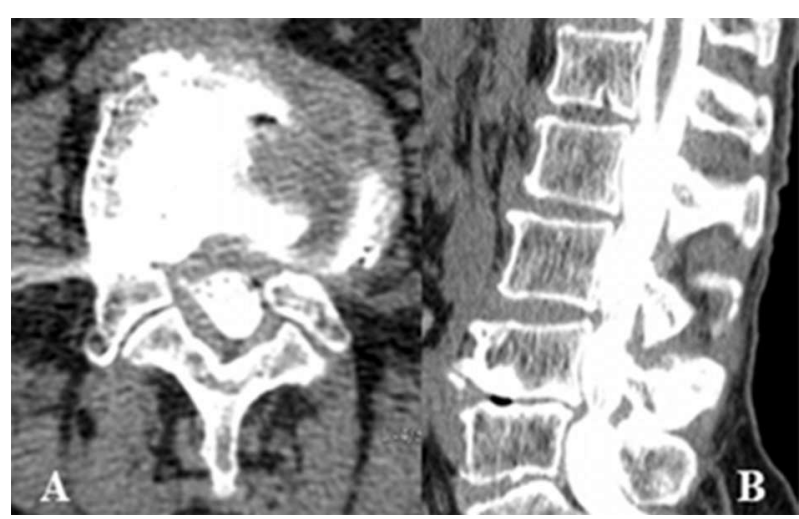

Fig. 3. CT-assisted lumbo-dorsal myelography (A/ axial view at $L_{4-5}$ level; $B$ / sagittal reconstruction): degenerative lumbar spinal stenosis at $L_{4-5}$ level.

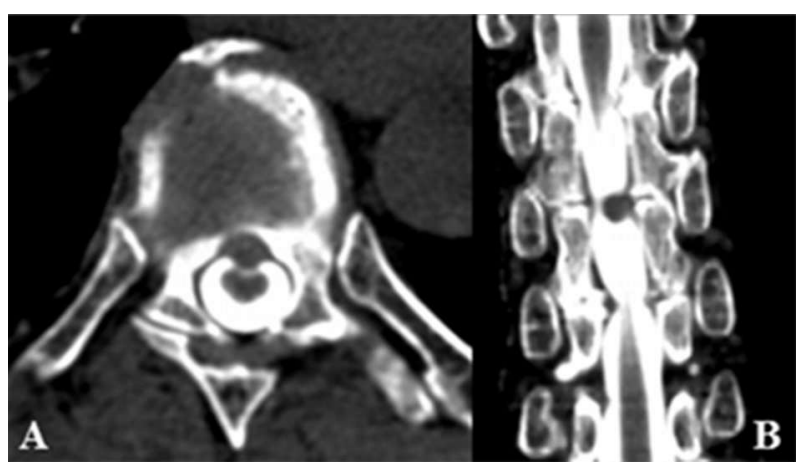

Fig. 4. CT-assisted lumbo-dorsal myelography (A/ axial view at $L_{4-5}$ level; $B$ / coronal reconstruction): degenerative thoracic spinal stenosis at $T h_{7-8}$ level.

\section{DISCUSSION}

Kim et al. present a large series of patients with clinical and neuroimaging evidence of degenerative lumbar spinal stenosis in combination with concurrent asymptomatic narrowing of the cervical or thoracic spinal canal (1). Asymptomatic cervical and thoracic stenosis must be diagnosed in time because neurological deterioration may sometimes occur as a result of continuous flexion or extension of the spine that causes spinal cord compression during the surgical procedure (10).

There are several publications that discuss the clinical presentation of the concomitant compression on the spinal cord and cauda equina, as well as the clinical signs that can deceive the physician to properly diagnose the spinal cord compression (2-8). The primary thoracic or thoraco-lumbar stenosis is rare, thus, physicians pay greater attention to the lumbar findings (11). The hypereflexia caused by myelopathy can be masked by the symptoms resulting from the 
Atanas Davarski, Ivo Kehayov, Tanya Kitova et al.

compression of cauda equina nerve roots $(3,5)$. All the three of our cases showed clinical signs of nerve root damage, and in Case 1, the knee and ankle jerk reflexes were absent. Case 2 and 3 showed apparent myelopathic signs of spinal cord compression.

The clinical presentation of epiconus medullaris or conus medullaris compression is manifested by pain and motor disturbance in the lower extremities which may resemble lumbar radiculopathy $(12,13)$. Toribatake et al. presented a series of 15 patients with lesions in the epiconus and conus medullaris region (between $\mathrm{Th}_{10}$ and $\mathrm{L}_{2}$ vertebra) who suffered from unilateral or bilateral muscle atrophy and sensory deficit. They also reported that the jerk reflexes were absent in $87 \%$ of the cases, $67 \%$ of the cases have had bowel and bladder disturbance and only $20 \%$ of the cases had pathological reflexes, suggesting upper motor neuron damage (11). Five patients were not properly diagnosed which resulted in inappropriate surgical treatment (11).

Patients with spinal stenosis at $\mathrm{L}_{1}-\mathrm{L}_{2}$ suffer from typical pain that irradiates to the gluteal region and the anterior surface of the thigh, the femoral nerve stretch test is usually positive (13). This statement was confirmed by the clinical presentation in our case №1 who suffered from pain in the gluteal region and the antero-lateral surface of the thigh accompanied by marked muscle hypotrophy of the left leg without symptoms of spinal cord compression.

\section{CONCLUSION}

We consider that physicians must perform thorough neurological examination of the spinal cord motor and sensory functions in all cases with suspected lumbar spinal stenosis. If there are even subtle signs of central damage, one should always recommend MRI of upper spinal segments. Thus, future neurological deterioration that may result from higher thoracic or cervical compression can be easily avoided.

The question whether to operate all of the affected spinal segments at a single or more stages is arguable. In our series, the patients were in a favorable general status which allowed us to perform single-staged surgical procedures on the two affected spinal segments in all three cases.

\section{REFERENCES}

1. Kim BS, Kim J, Koh HS, Han SY, Lee DY, Kim KH. Asymptomatic cervical or thoracic lesions in elderly patients who have undergone decompressive lumbar surgery for stenosis. Asian Spine J. 2010;4:65-70.

2. Hioki A, Miyamoto K, Hosoe H, Fukuta S, Shimizu K. Two-stage decompression for combined epiconus and cauda equina syndrome due to multilevel spinal canal stenosis of the thoracolumbar spine: a case report. Arch Orthop Trauma Surg. 2008;128:955-958.

3. Fushimi K, Miyamoto K, Hioki A, Hosoe H, Takeuchi A, Shimizu K. Neurological deterioration due to missed thoracic spinal stenosis after decompressive lumbar surgery. Bone Joint J. 2013; 95-B:1388-1391.

4. Valls PL, Naul LG, Kanter SL. Paraplegia after a routine lumbar laminectomy: report of a rare complication and successful management. Neurosurgery. 1990;27:638-640.

5. Takeuchi A, Miyamoto K, Hosoe H, Shimizu K. Thoracic paraplegia due to missed thoracic compressive lesions after lumbar spinal decompression surgery: report of three cases. J Neurosurg. 2004;100(Suppl Spine):71-74.

6. Bozkurt M, Göçmez C, Okçu M, Türkcü G, Em S, Oktayoğlu P, et al. Paraplegia due to missed thoracic meningioma after lumbar spinal decompression surgery: A case report and review of the literature. Dicle Tip Dergisi / Dicle Medical Journal. 2014; 41 (1): 210-213.

7. Ko S-B, Lee S-W, Shim J-H. Paraplegia due to Missed Thoracic Meningioma after Laminotomy for Lumbar Spinal Stenosis: Report of Two Cases. Asian Spine J. 2011;5(4):253-257.

8. Dagi T, Tarkington MA, Leech JJ. Tandem lumbar and cervical spinal stenosis: natural history, prognostic indices, and results after surgical decompression. J Neurosurg. 1987;66:842-849.

9. Kikuike K, Miyamoto K, Hosoe H, Shimizu K. One-staged combined cervical and lumbar decompression for patients with tandem spinal stenosis on cervical and lumbar spine: analyses of clinical outcomes with minimum 3 years follow-up. J Spinal Disord Tech. 2009;22:593-601.

10. Langmayr JJ, Ortler M, Obwegeser A, Felber S. Quadriplegia after lumbar disc surgery: a case report. Spine (Phila Pa 1976). 1996;21:1932-1935. 
11. Barnett GH, Hardy RW Jr, Little JR, Bay JW, Sypert GW. Thoracic spinal canal stenosis. J Neurosurg. 1987;66:338-344.

12. Toribatake $Y$, Baba H, Kawahara N, Mizuno K, Tomita K. The epiconus syndrome presenting with radicular-type neurological features. Spinal Cord. 1997;35:163-170.

13. Lee S-Ho, Seokmin Choi S. L1-2 Disc Herniations: Clinical Characteristics and Surgical Results. J Korean Neurosurg Soc. 2005 (38): 196-201. 